The first lessons of a wide-scale pneumococcal infection vaccinal prevention program in the Sverdlovsk Region

\title{
Author affiliation:
}

Romanenko Viktor Vasil'evich, $\mathrm{PhD}$, deputy head doctor at the Hygiene and Epidemiology Center of Sverdlovsk Region (Federal Budgetary Healthcare Institution).

Address: 3, Otdelnyi ln., Yekaterinburg, 620078, tel.: +7 (343) 374-13-79, e-mail: Romanenko_vv@66.rospotrebnadzor.ru

Article received: 12.11.2013. Accepted for publication: 14.01.2014.

The article is dedicated to vaccination against pneumococcal infection. The authors present vaccination results in 4 pilot districts of the Sverdlovsk Region. If necessary, lectures and classes were conducted in order to increase vaccination coverage of the target cohort of children and improve awareness of medical personnel and parents. 18,307 children were vaccinated 2 and 3 times in May-September 2013. Analysis of the post-vaccination children's condition and undesirable phenomena demonstrated low reactogenicity and good vaccine tolerance.

Key words: pneumococcal infection, National calendar, vaccination, tolerance, undesirable phenomena, children.

High social significance of pneumococcal infections (PI) requires development and implementation of preventive measures aimed at reducing PI morbidity, preventing generalized forms of the disease and reducing incapacitation and mortality rates among young children and adults. According to the World Health Organization (WHO), vaccination is the only effective measure against PI. It should be mentioned that the need in PI vaccines has become especially crucial in recent years due to rapid spread of antibacterial resistance among pneumococci.

The leading organizations under the UN authority recommend cohort vaccination of children against the pneumococcal infection: "The WHO and UNICEF have recognized the safety and effectiveness of pneumococcal conjugate vaccines and recommend that these vaccines for young children be included in national immunization programs". Pneumococcal vaccination is implemented in 56 states: it is introduced throughout the country in 54 states; in 2 states - only in several regions. Routine use of pneumococcal conjugate vaccines (PCVs) dramatically reduced morbidity due to invasive forms of the pneumococcal infection (IPIs) in many countries; moreover, IPIs caused by vaccinal bacterial serotypes have virtually ceased to exist even among the non-target (as per the immunization program) age groups (community immunity effect).

The Government of Russia has planned to include vaccination against the pneumococcal infection in the National Vaccination Calendar of Russia in 2014. Pneumococcal conjugate vaccines have been available in Russia since 2008; they have been used in several regions in the framework of the regional programs.

The registration of pneumonias was first introduced in the Sverdlovsk Region by the orders Nos. 139-p and 01/1-63 of 16.03.2002 "On the introduction of pneumonia morbidity registration in the Sverdlovsk Region" of the Ministry of Health of the Sverdlovsk Region and the Hygiene and Epidemiology Center for the Sverdlovsk Region (Federal State Institution). Thus, there are regional data for more than 10 past years (pic. 1).

A steady tendency to the morbidity rate increase among the population of the region is observed in the 10-year-long (2002-2012) pneumonia morbidity dynamics. Within the period under analysis, the morbidity rate has increased 2.8 times - from 224.4 per 100,000 in 2002 to 626.3 per 100,000 in 2013 . The long-term mortality dynamics demonstrate a similarly unfavorable tendency to increase: the mortality rate increased eightfold. 
Long-term age morbidity structure analysis allows distinguishing two groups with the highest rates: children under 2 years of age and persons over 60 years of age; morbidity rates among them exceed the average morbidity rate 4.3 and 2.9 times, respectively (pic. 2).

Community-acquired pneumonia is ubiquitous throughout the Sverdlovsk Region. However, morbidity rates in several municipalities significantly exceed the average regional rate. The highest morbidity rates are registered in the cities of Kamensk-Uralski, Asbest, Kachkanar, Revda, Polevskoi, Bogdanovich and Verkhotur'e (pic. 3).

The Regional Vaccination Calendar providing for vaccination of children over 2 months of age against the pneumococcal infection was adopted in the region in 2008. However, budgeting of the program of vaccinal prevention against this infection is limited and is sufficient to provide preventive vaccines only to infant orphanage inmates.

Regional healthcare authorities and the Federal service on customers' rights protection and human well-being surveillance brought a proposal to conduct a pilot project of single-stage vaccination of several age groups (from 2 months of age to 5 years of age inclusively) against the pneumococcal infection. Four pilot territories of the Sverdlovsk Region (Asbest, Polevskoi, Revda and Kachkanar) with the highest rates of morbidity due to community-acquired pneumonias among children and adults according to the retrospective epidemiologic analysis were determined for the project implementation. The additional criteria for pilot territory selection were the following:

- High motivation of the local administration and medical personnel for implementation of prevention programs against pneumococcal infections;

- $\quad$ Existence of a network of licensed vaccinal prevention wards at medical facilities and child care centers;

- $\quad$ Developed cold chain system;

- Availability of district pediatricians and highly specialized doctors (pulmonologists, otolaryngologists) at medical facilities;

- High motivation of the local population for administration of preventive vaccines due to the long-term local health communication;

- Successful experience of implementing programs of cohort immunization with non-calendar vaccines against hepatitis A, tick-borne encephalitis, influenza and chickenpox in these cities;

- $\quad$ Availability of computer equipment and software (computer workstations (CWSs) for immunologists and CWS-epidemiologists) for immunization data registration and analysis.

The second stage involved implementation of a wide-scale organizational and methodological work:

- Several working conferences involving heads of local administration and medical facilities;

- $\quad$ Theoretical and practical conference for medical personnel;

- $\quad$ Specification of age groups and listing of persons to be vaccinated;

- Health communication with the local population, primarily with parents.

Moreover, the project provided for individual work with parents, which resulted in compulsory signing of documents of informed consent to vaccination by parents.

One of the negative issues that the Kachkanar pediatricians encountered in the framework of the project implementation was refusal of most parents to sign the informed consent documents, the stated reason being negative publications in the local press and information on the Internet. Therefore, a conference involving medical personnel and health communication to parents were organized with the participation of the regional level doctors. As a result, half of the objectors consented to vaccination. In the other territories the program was implemented up to schedule.

Another issue that the pediatricians encountered in the framework of implementation of the program of vaccinal prevention against the pneumococcal infection was the lack of combined vaccines supplied to the territories and paid for from the public funds; this led to a high injection stress, especially among children of 3-6 months of age. That is why it was found necessary to 
breach administration schedule of the other calendar vaccines in the territories where children under 7 months of age were vaccinated, particularly, in Asbest. For this reason the percentage of children under 7 months of age vaccinated against the pneumococcal infection in the other three cities was insignificant. Generally, children received vaccination at 7 months of age according to the schedule " $2+1$ "; children from 12 months of age to 5 years 11 months 29 days of age were administered the vaccine twice, 2 months apart.

The program was launched in May 2013, when 40 thousand doses of conjugate vaccine Synflorix against the pneumococcal infection were supplied to the region; they were further delivered to vaccination wards of medical facilities in the pilot territories in line with the cold chain requirements. 18,307 children in tote were vaccinated in May-September 2013 two and three times. The children who started to receive vaccination before the age of 1 year will be administered the third vaccine in Q1 2014. The total number of the vaccinated persons and territory coverage are given in tb. 1.

The vaccination was conducted in strict compliance with the drug prescription information and other regulatory documents. The system of adverse phenomena registration was active-passive. Upon signing of an informed consent document, the parents undertook to report any adverse postvaccinal phenomena; moreover, medical personnel selectively telephoned parents on postvaccinal day 5-6 (tb. 2).

Abnormal reactions and complications were not registered in most municipalities. All reactions were registered on the municipal level in branches of the Hygiene and Epidemiology Center for the Sverdlovsk Region (Federal Budgetary Healthcare Institution).

Analysis of adverse phenomena revealed the following peculiarities:

- $\quad$ Reddening in the site of injection constituted $47 \%$ of all the adverse reactions;

- $\quad$ Fever up to $38{ }^{\circ} \mathrm{C}$ was registered in $31 \%$ of the vaccinated persons;

- $\quad$ Most adverse reactions were registered in children of 2-5 years of age. What stands out is the lack of adverse phenomena in the children who started to receive vaccination before 6 months of age.

According to the program, the children (both vaccinated and not vaccinated against PI) in the four pilot territories will remain under medical monitoring for the next two years (2014/15) in order to evaluate the vaccine's epidemiologic and clinical efficacy and its effect on morbidity due to pneumococcal community-acquired pneumonias, otites and meningites.

\section{CONCLUSION}

The program of cohort vaccination of children of 6 age groups against PI was successfully implemented in four pilot territories of the Sverdlovsk Region, which demonstrated low reactogenicity and high acceptability of vaccine Synflorix.

The expert community and healthcare authorities need to review the vaccination calendar before introducing vaccinal prevention against the pneumococcal infection to the National Vaccination Calendar of Russia. As long as, on the one hand, the pneumococcal infection is most dangerous for children under 1 year of age, on the other hand, the children of this age group demonstrate the highest tolerance to the vaccine, it is only reasonable to vaccinate children at the youngest age possible from the personal and community health points of view. In order to achieve the highest program efficacy it is necessary to raise an issue of a fixed place of prevention against the pneumococcal infection in the Vaccination Calendar. It is reasonable to raise an issue of introducing combined vaccines with a big number of antigens in order to execute the National Vaccination Calendar.

\section{REFERENCES}

1. Pneumococcal vaccines - WHO position paper, 2012, No. 14. 2012; 87: 129-144. Available at: http://www.who.int/wer. 
2. Available at: http://who.int./immunization_monitoring/Global_Immunization_Data.pdf. Accessed: September 27, 2012.

Pic. 1. Long-Term Dynamics of Pneumonic Morbidity and Mortality Rate in Sverdlovsk Region (per 100000 people)

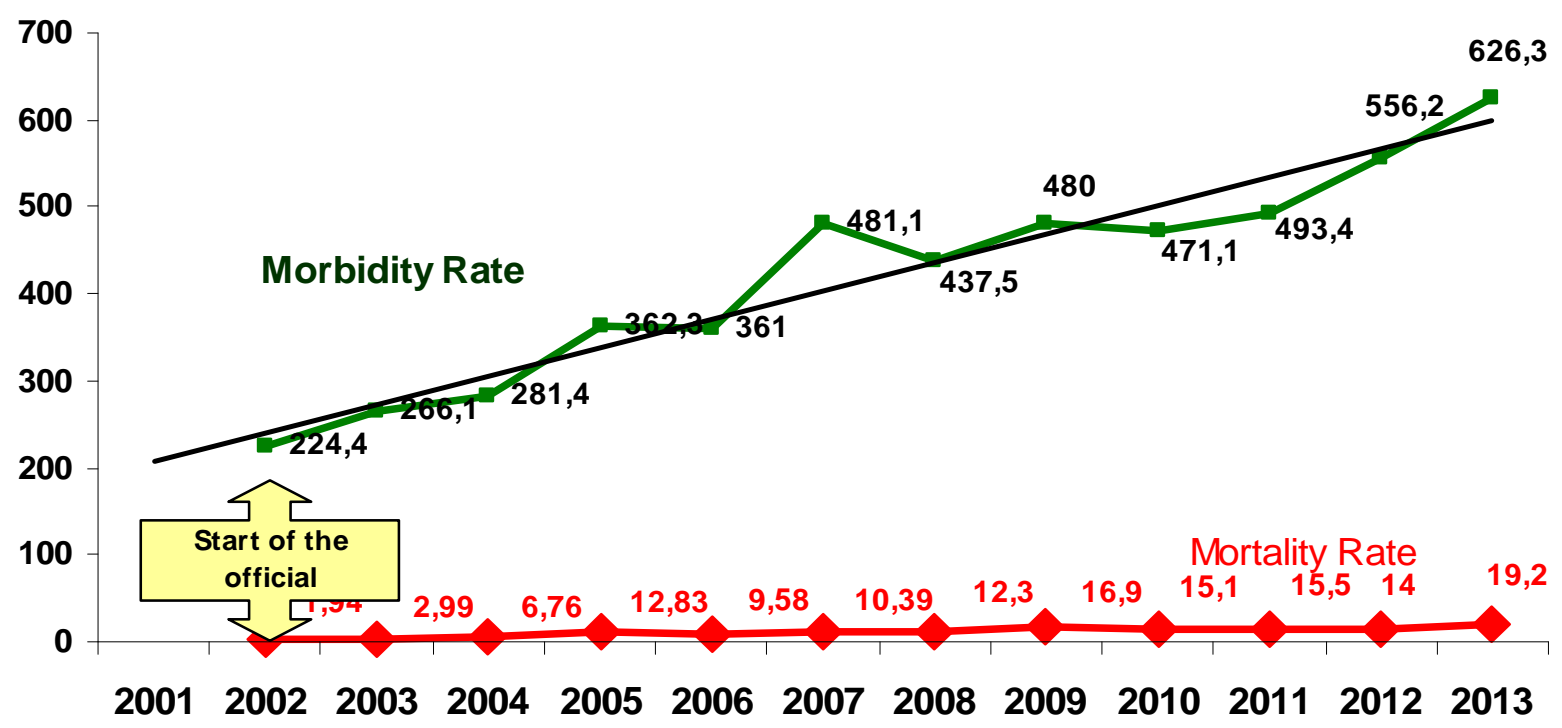

Pic. 2. Pneumonic Morbidity Rate in Various Age Groups in Sverdlovsk Region (LongTerm Average Annual Level over the Period of 10 Years per 100000 people)

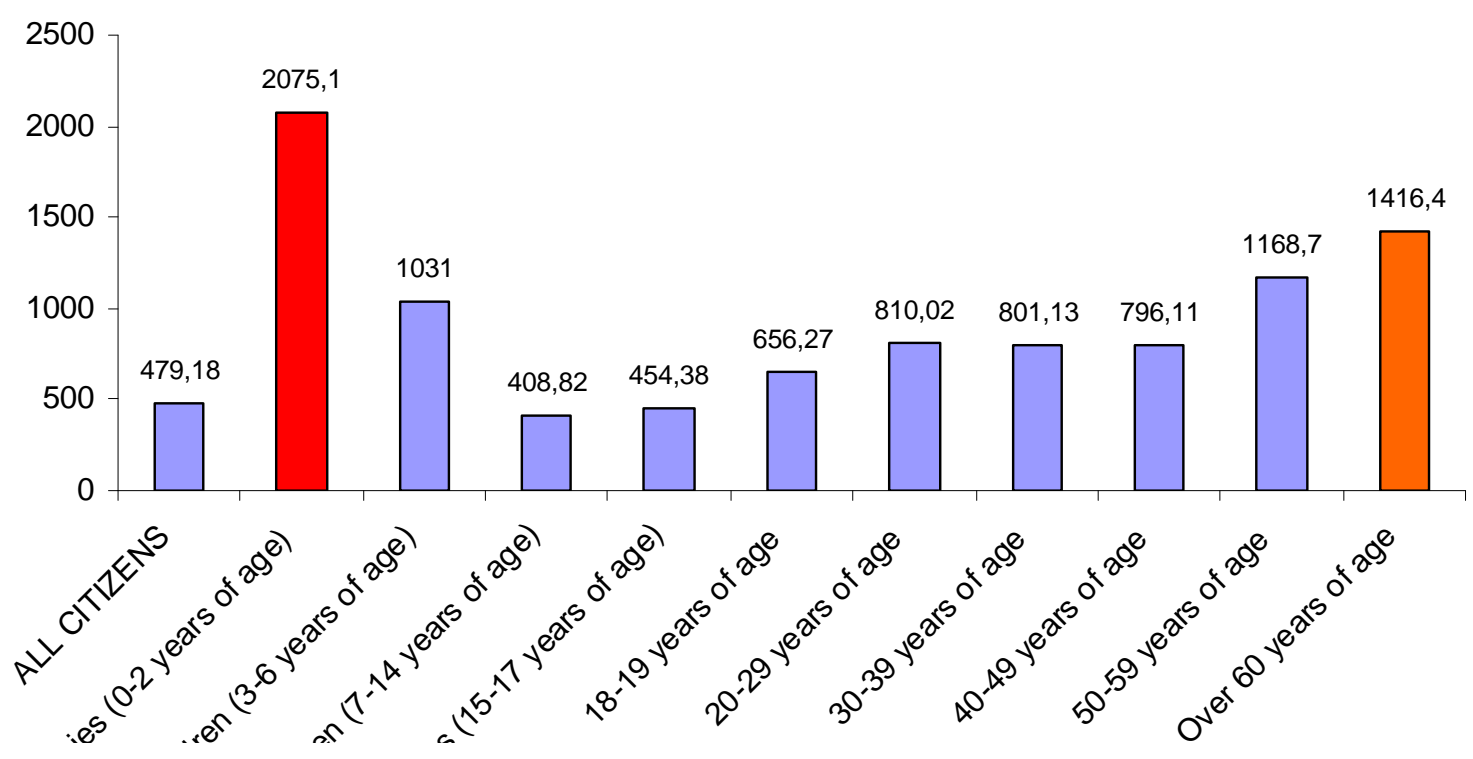




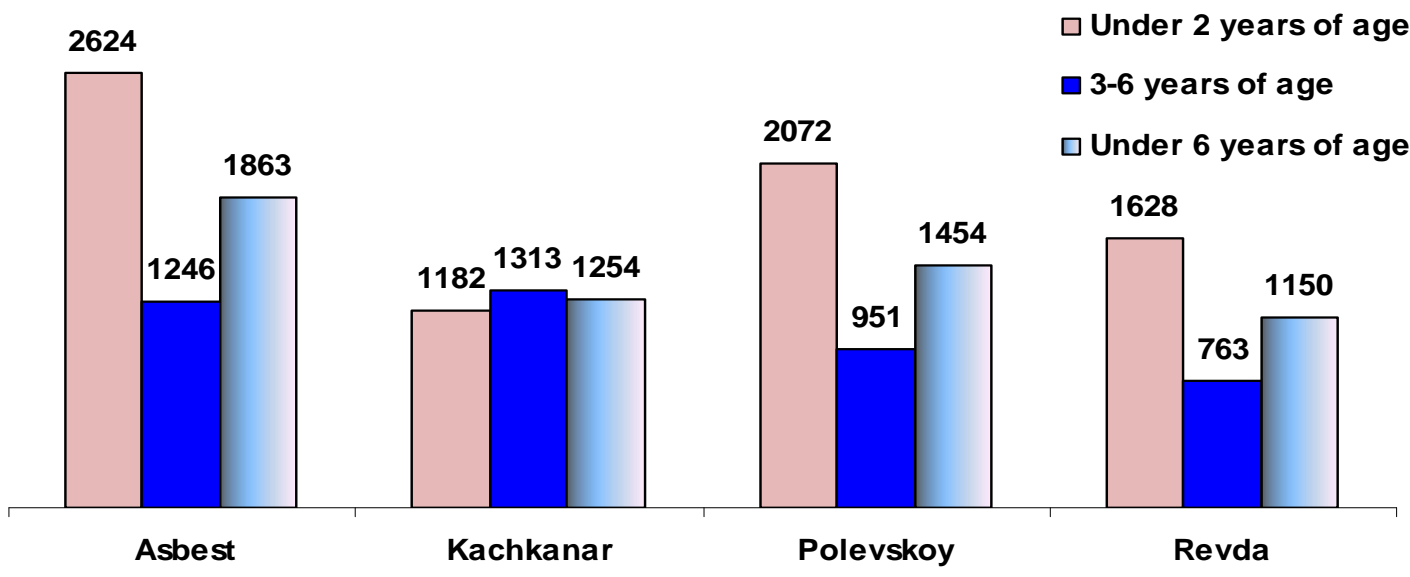

\begin{tabular}{|c|c|c|c|c|c|c|c|c|c|c|}
\hline \multirow{2}{*}{$\begin{array}{c}\text { Pilot } \\
\text { Territories }\end{array}$} & \multicolumn{2}{|c|}{6 weeks -6 months } & \multicolumn{2}{|c|}{ 7-11 months } & \multicolumn{2}{|c|}{$12-23$ months } & \multicolumn{2}{|c|}{2 years -5 years } & \multirow{2}{*}{$\begin{array}{l}\text { Vaccinated } \\
\text { with } 2 \text { or } \\
\text { more } \\
\text { vaccines }\end{array}$} & \multirow{2}{*}{$\begin{array}{c}\text { No. of } \\
\text { vaccines } \\
\text { used }\end{array}$} \\
\hline & $\begin{array}{l}\text { Vaccinated } \\
\text { with } 2 \text { or } \\
\text { more } \\
\text { vaccines }\end{array}$ & $\begin{array}{c}\text { Coverage, } \\
\%\end{array}$ & $\begin{array}{l}\text { Vaccinated } \\
\text { with } 2 \text { or } \\
\text { more } \\
\text { vaccines }\end{array}$ & $\begin{array}{c}\text { Coverage, } \\
\%\end{array}$ & $\begin{array}{l}\text { Vaccinated } \\
\text { with } 2 \text { or } \\
\text { more } \\
\text { vaccines }\end{array}$ & $\begin{array}{c}\text { Coverage, } \\
\%\end{array}$ & $\begin{array}{l}\text { Vaccinated } \\
\text { with } 2 \text { or } \\
\text { more } \\
\text { vaccines }\end{array}$ & $\begin{array}{c}\text { Coverage, } \\
\%\end{array}$ & & \\
\hline Kachkanar & 23 & 11 & 70 & 26,9 & 270 & 56,3 & 1072 & 60,1 & 1435 & 2946 \\
\hline Asbest & 380 & 89,2 & 364 & 98,4 & 786 & 86,5 & 1348 & 38,4 & 2878 & 6500 \\
\hline Polevskoy & 36 & 8,6 & 289 & 56,3 & 777 & 76,6 & 2478 & 64,4 & 3580 & 7485 \\
\hline Revda & 24 & 6,5 & 194 & 49,1 & 536 & 69,5 & 2310 & 99,9 & 3064 & 6346 \\
\hline Other cities & & & & & & & 7350 & 8,0 & 7350 & 14700 \\
\hline Total & 463 & 3,0 & 917 & 6,2 & 2369 & 8,0 & 14558 & 14,0 & 18307 & 37977 \\
\hline
\end{tabular}

Table 1. Number of children under 6 years of age vaccinated with pneumococcal conjugate vaccine in Sverdlovsk region over the period of May-October, 2013. 
Table 2. Postvaccinal adverse effects were analyzed within the framework of a pilot project in Asbest, Krasnoufimsk, and Yekaterinburg (9750 vaccines in total).

\begin{tabular}{|c|c|c|c|c|c|}
\hline \multirow[t]{2}{*}{ Character of Complications } & \multicolumn{4}{|c|}{ Age } & \multirow[t]{2}{*}{ Total } \\
\hline & $\begin{array}{l}6 \text { weeks - } \\
6 \text { months }\end{array}$ & $\begin{array}{c}7-11 \\
\text { months }\end{array}$ & $\begin{array}{l}\mathbf{1 2 - 2 3} \\
\text { months }\end{array}$ & $\begin{array}{l}2 \text { years }- \\
5 \text { years }\end{array}$ & \\
\hline Irritability & & & 2 & 2 & $4(3,9 \%)$ \\
\hline Pain in the Site of Injection & & & 2 & 3 & $5(4,9 \%)$ \\
\hline Reddening in the Site of Injection & & 5 & 7 & 35 & $\begin{array}{c}47 \\
(45,6 \%)\end{array}$ \\
\hline Inflation in the Site of Injection & & 1 & 3 & 9 & $\begin{array}{c}13 \\
(12,6 \%)\end{array}$ \\
\hline Fever & & 3 & 2 & 26 & $\begin{array}{c}31 \\
(30,1 \%)\end{array}$ \\
\hline $\begin{array}{l}\text { Induration and Hemorrhage in the Site of } \\
\text { Injection }\end{array}$ & & & 2 & 1 & $3(2,9 \%)$ \\
\hline Other & & & & & \\
\hline Total & & $9(8,3 \%)$ & $18(17,5 \%)$ & $76(73,8 \%)$ & $\begin{array}{c}103 \\
(1,1 \%)\end{array}$ \\
\hline
\end{tabular}

